\title{
Experimental and numerical analysis of the dynamic behaviour in tension of an armour steel for applications in defence industry
}

\author{
Ezio Cadoni ${ }^{1, \text { a }}$, Matteo Dotta ${ }^{2}$, Daniele Forni ${ }^{1,2}$, Gianmario Riganti ${ }^{1}$, and Hanspeter Kaufmann ${ }^{3}$ \\ ${ }^{1}$ DynaMat Laboratory, University of Applied Sciences of Southern Switzerland, 6952 Canobbio, Switzerland \\ ${ }^{2}$ Department of Structural, Geotechnical and Building Engineering - Politecnico di Torino, 10129 Torino, Italy \\ ${ }^{3}$ RUAG Defence AG, 3602 Thun, Switzerland
}

\begin{abstract}
The dynamic behaviour of armour steel in tension was investigated over a wide range of strain-rates on round specimens. The experiments were carried out by means of a Split Hopkinson Tensile Bar device and by a Hydro Pneumatic Machine. The target strain rate were set at the following six levels: $10^{-3}, 5,25,100,500$ and $1000 \mathrm{~s}^{-1}$. Two material models were calibrated and used to replicate the experiments and to simulate blasting event on steel plate. Finally, the two responses are compared.
\end{abstract}

\section{Introduction}

The armour steels are widely used in protection of particular structures (i.e. vehicles, buildings, personnel etc.). Those structures are designed to withstand severe dynamic events such as impact or blasting loads. In order to improve the degree of protection and to provide optimized solution for safety is fundamental the knowledge of the armour steel under the same conditions generated in real dynamic events. These processes cannot be analysed without numerical simulations. However, accuracy and realistic structural assessment are highly influenced by the material modelling. Hence, it is recommended to investigate the material responses in a wide range of strain rates.

This work investigates the dynamic behaviour of high hardness armour steel (HBW 570-640) in tension at different strain rate such as $10^{-3}, 5,25,100,500$ and $1000 \mathrm{~s}^{-1}$. The test data were analysed with the purpose to identify material parameters. Two techniques were applied: the calibration of well-known model and the reverse simulation of the Split Hopkinson Tensile Bar (SHTB) test [1]. Material models developed were assessed and discussed by means of a numerical example of blast on steel plate.

\section{Material}

The high hardness armour steel here analysed is a commercial material product used in the construction of defence vehicles or in temporary structures when high level of protection is required. The Ultimate Tensile Strength is higher than $2 \mathrm{GPa}$ while the yield strength is typically higher than $1.5 \mathrm{GPa}$. The elastic modulus is $207 \mathrm{GPa}$, density is $7850 \mathrm{~kg} / \mathrm{m}^{3}$ and the melting temperature is $1800 \mathrm{~K}$. The chemical compositions of the armour steel is shown in Table 1.

\footnotetext{
a Corresponding author: ezio.cadoni@supsi.ch
}

Table 1. Chemical composition according to the manufacture.

\begin{tabular}{|c|c|}
\hline $\mathrm{C} \max \%$ & 0.470 \\
\hline $\mathrm{Si} \%$ & 0.700 \\
\hline $\mathrm{Mn} \max \%$ & 1.000 \\
\hline $\mathrm{P} \max \%$ & 0.010 \\
\hline $\mathrm{S} \max \%$ & 0.005 \\
\hline $\mathrm{Cr} \max \%$ & 1.500 \\
\hline Ni max \% & 3.000 \\
\hline Mo max \% & 0.700 \\
\hline $\mathrm{B} \max \%$ & 0.005 \\
\hline
\end{tabular}

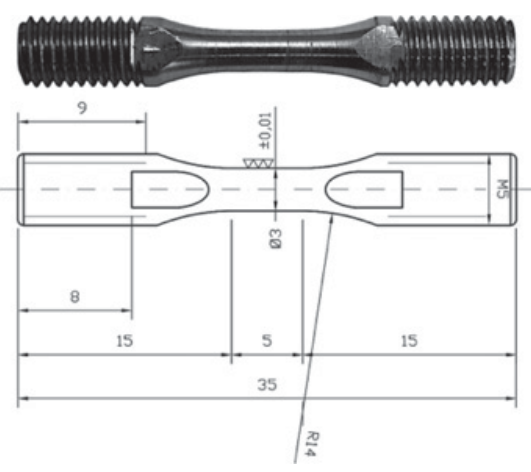

Figure 1. Specimen geometry.

\subsection{Specimens}

Round samples having $3 \mathrm{~mm}$ in diameter and $5 \mathrm{~mm}$ of gauge length have been used (see Fig. 1) [2-8].

\section{Experimental set-up}

Tensile testing at several strain-rates has been performed using different experimental set-ups. All tests were performed at room temperature, and the target strain-rates were set at the following six levels: $10^{-3}, 5,25,100,500$

This is an Open Access article distributed under the terms of the Creative Commons Attribution License 4.0, which permits unrestricted use, distribution, and reproduction in any medium, provided the original work is properly cited. 


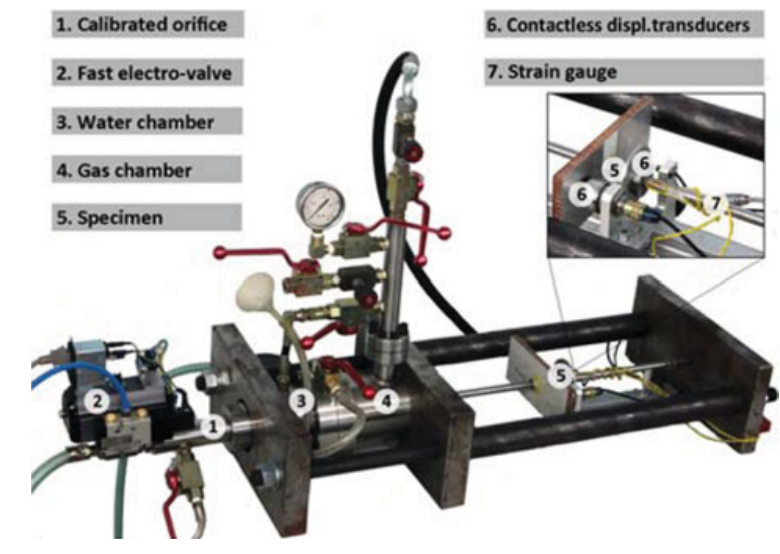

Figure 2. Hydro-Pneumatic Machine.

and $1000 \mathrm{~s}^{-1}$. At least three tensile tests were carried out for each strain-rate.

\subsection{Quasi-static tests}

Quasi-static tests have been performed by means of an universal electromechanical testing machine Zwick/RoellZ50 which has the maximum load bearing capacity of $50 \mathrm{kN}$.

\subsection{Intermediate strain-rate}

Intermediate strain-rate behaviour in tension has been investigated by means of a hydro-pneumatic machine (HPM), whose scheme is reported in Fig. 2.

The functioning of the machine is described in $[4,6]$.

\subsection{High strain rate}

The high strain-rate tests have been performed using a Split Hopkinson Tensile Bar [6] that consists into two cylindrical high strength steel bars, having a diameter of $10 \mathrm{~mm}$, with a length of respectively 9 and 6 meters for input and output bar, as represented in Fig. 3.

The armour steel specimen is assembled between the two bars. Input and output bars were instrumented with strain gauges which measure incident, reflected and transmitted pulses acting on the specimen cross section.

The present set-up has the following condition: i) the bar diameter $(10 \mathrm{~mm})$ is small in comparison with the pulse length $(12 \mathrm{~m})$; ii) the specimen length is short so that the time taken by the wave to propagate through the specimen is short compared to the total time of the test. This condition allows many reflections inside the specimen necessary for reaching a homogeneous stress and strain distribution along the specimen gauge length, what means also equilibrium of the forces acting on both ends of the specimen.

Having fulfilled the conditions i) and ii) and being the two bars elastically loaded the one-dimensional elastic plane stress wave propagation theory can be applied to the input bar-specimen-output bar system as it is extensively shown in [4-8], where the three relationships are proofed which allow to calculate the stress, the strain and the strain rate in the specimen material versus time from the records

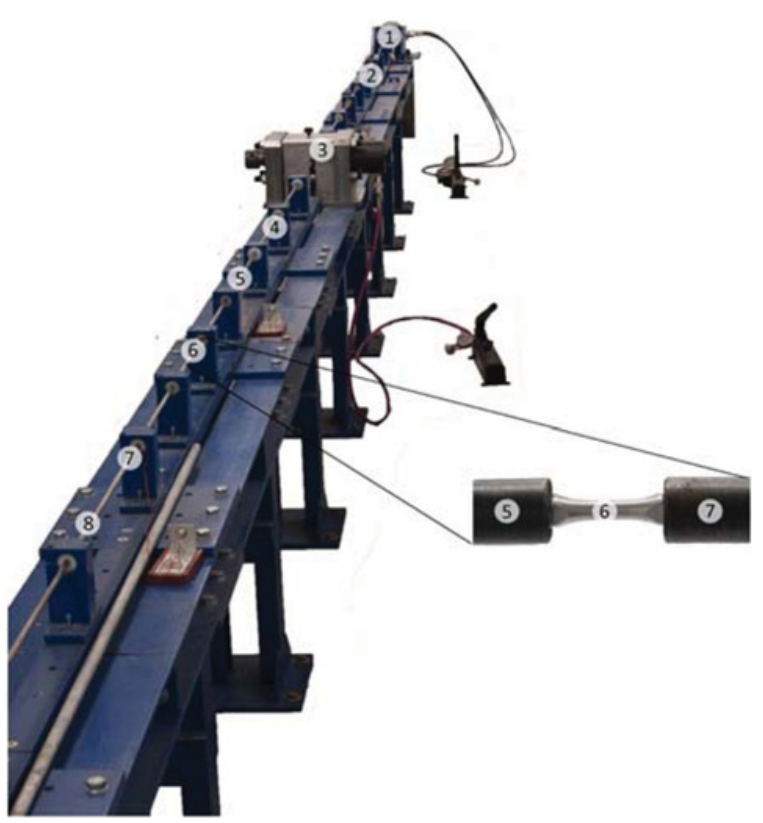

Figure 3. Split Hopkinson Tensile Bar device.

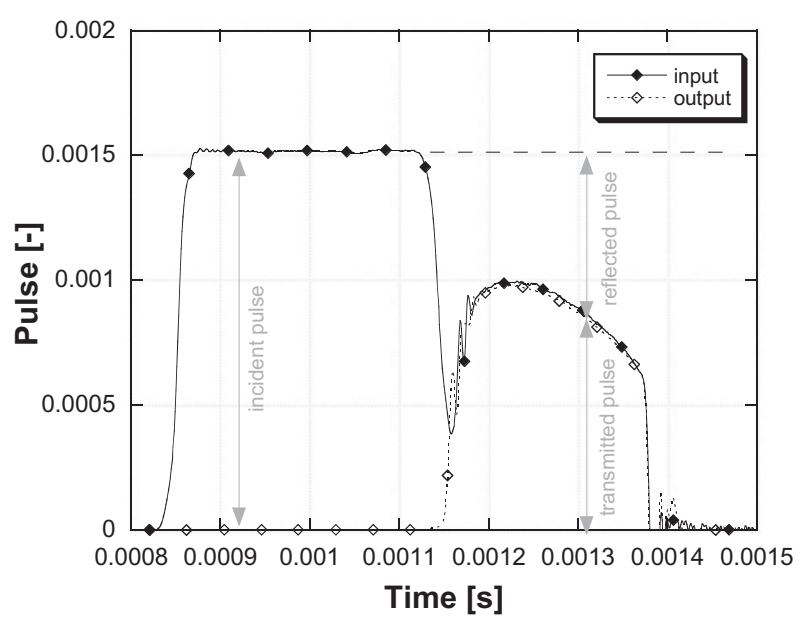

Figure 4. Signals obtained during a dynamic test @ $1000 \mathrm{~s}^{-1}$.

of the incident $\left(\varepsilon_{I}\right)$, reflected $\left(\varepsilon_{R}\right)$ and transmitted $\left(\varepsilon_{T}\right)$ pulses.

$$
\begin{gathered}
\sigma_{E}(t)=E_{0} \frac{A_{0}}{A} \varepsilon_{T}(t) \\
\varepsilon_{E}(t)=-\frac{2 C_{0}}{L} \int_{0}^{t} \varepsilon_{R}(\tau) d \tau \\
\dot{\varepsilon}_{E}(t)=\frac{2 C_{0}}{L} \varepsilon_{R}(t)
\end{gathered}
$$

where, $E_{0}$ is the bars elastic modulus, $A_{0}$ is the bars crosssectional area, $A$ is the specimens cross-sectional area, $L$ is the specimen gauge length and $C_{0}$ is the sound velocity of the bar material.

In Fig. 4 the signals for a SHTB test @ $1000 \mathrm{~s}^{-1}$ are shown. By using these signals and the equations (1) and (3) it is possible describe the history of the strain rate and of the stress (see Fig. 5). Thanks to the length of the SHTB 


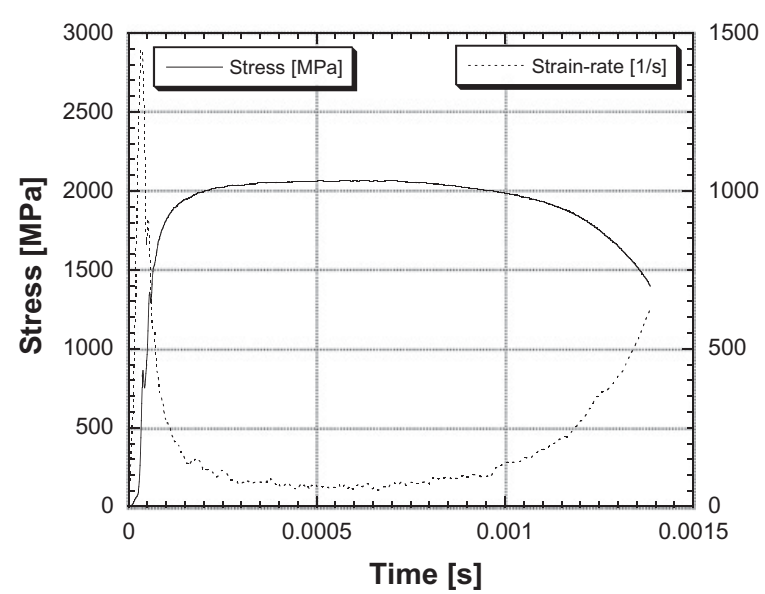

Figure 5. Engineering stress and strain-rate vs. time $100 \mathrm{~s}^{-1}$.

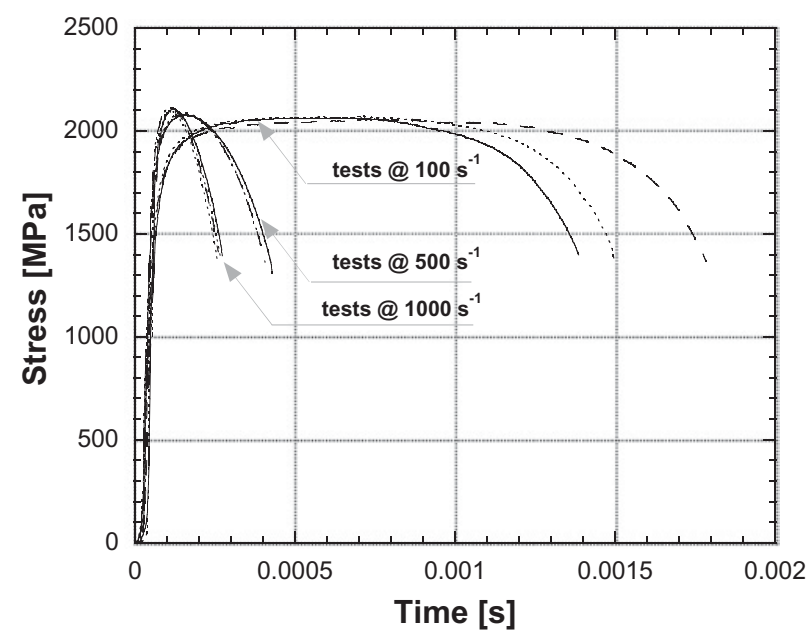

Figure 6. Engineering stress vs. time curves.

device and the strength of this armour steel, strain rates a little bit lower than $100 \mathrm{~s}^{-1}$ were obtained, as shown in Fig. 5. This fact is guaranteed by the constancy of the strain rate during the deformation in the plastic region.

\section{Results}

By using different pre-loads in the pre-tensioned bar is possible to obtain different strain rates such as 100, 500 and $1000 \mathrm{~s}^{-1}$ (see Fig. 6).

The armour steel analysed shows quite low strain rate sensitivity. This can be observed in Fig. 7 where the true stress versus true strain curves at different high strain-rates are depicted.

Analysing Fig. 8, a better and brief representation of the strain-rate sensitivity can be highlighted. Here the trends of the yield stress $\left(\mathrm{R}_{0.2}\right)$, the ultimate tensile strength $\left(\mathrm{R}_{\mathrm{m}}\right)$ and the fracture stress $\left(\mathrm{R}_{\mathrm{u}}\right)$ are reported as function of the strain-rate. In the same plots also the uniform and the reduction in cross-sectional area $(\mathrm{Z})$ are shown. For each of these trends, a visual trend line is included to help distinguish the data sets.

The characteristics of fracture as the reduced area of the specimen cross section after failure in the necking zone as well as the fracture strain, have been obtained by

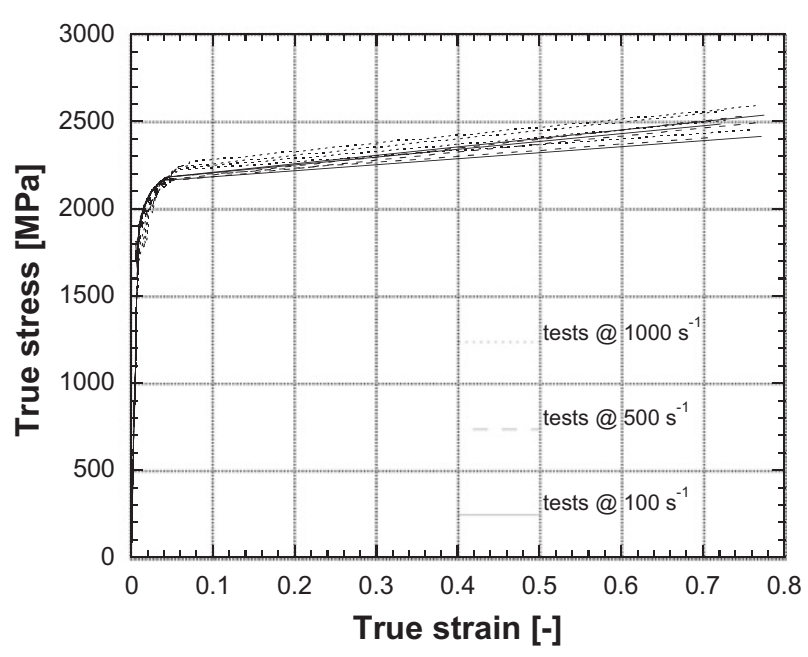

Figure 7. True stress vs. true strain at different strain-rates.

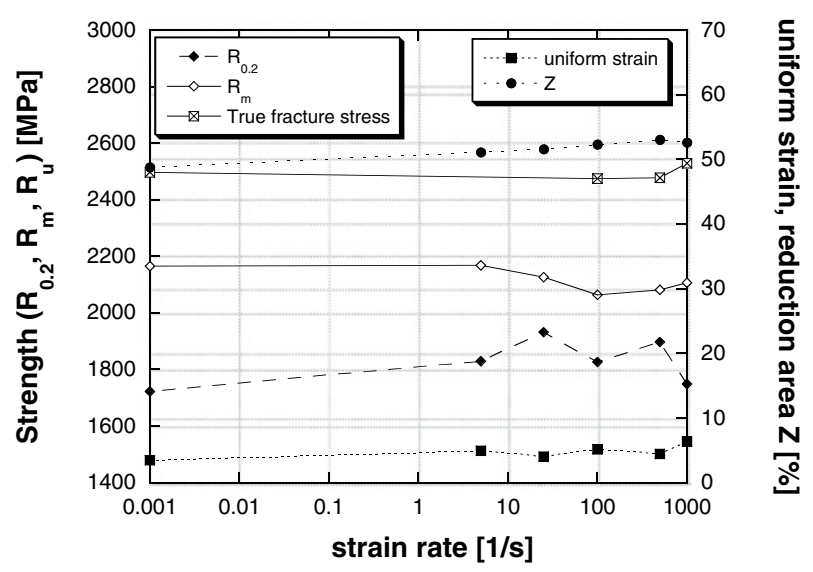

Figure 8. Mechanical properties in function of the strain-rate.

means of two images taken before and after the test of each specimen, as shown in Fig. 9. In order to do this, the specimen is at best reconstructed by bringing together the two broken parts and both the diameter and the meridional radius of curvature at the reduced section have been measured. Post-mortem examination of the specimens has also been made after fracture obtaining measurement of the diameter and the meridional radius of curvature at the reduced section that are used for the last point of the true stress-strain diagram by the Bridgman formula.

In Fig. 9 can be observed the differences between the specimen after quasi-static and high strain rate tests. In the quasi-static the necking zone is larger than the dynamic one, this means that in dynamic the deformation is more localized.

\section{Numerical analysis}

The numerical analysis of the dynamic behaviour of armour steel in tension was conducted using the obtained experimental results. The aim of this study was to verify the capacity of the material constitutive models to replicate the material response in case of dynamic events. In particular, two procedures were chosen. The first was the use of the Johnson-Cook model [9] calibrated with the experimental results, the second was the use of 

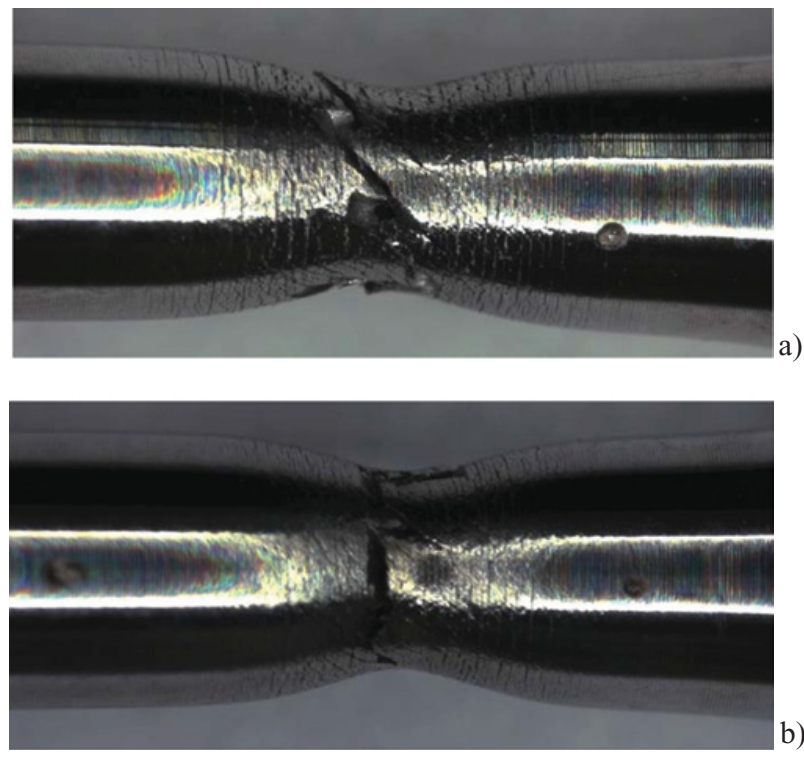

Figure 9. Photos of specimens after test: a) static; b) $1000 \mathrm{~s}^{-1}$.

the *MAT_PIECEWISE_LINEAR_PLASTICITY model, present in LS-Dyna code, calibrated on the experimental signals. These two procedures were used in the FEM simulation of the dynamic tensile test carried out with the SHTB. A second assessment was performed simulating numerically a blasting event on an armour steel plate.

\subsection{Calibration of the material model}

Dynamic response of materials is usually expressed through models based on the viscoplasticity theory.

They are usually expressed as the product of functions of key variables such as temperature, strain rate, stress and strain, as in Eq. (4).

$$
\sigma_{y}(\varepsilon, \dot{\varepsilon}, T)=f\left(\sigma_{y}, \varepsilon\right) \cdot g(\dot{\varepsilon}) \cdot h(T) .
$$

Equation of state can be further added to this basic formulation in order to represent pressure-volumeenergy/temperature relation.

Those material models are capable to represent the strain rate sensitivity, plasticity and are widely used in impact, ballistic, blast, and crash event simulations.

Among the advantages of those models can be highlighted: the simplicity in use; limited number of dynamic tests to identify dynamic sensitivity; the use of quasi-static stress strain to identify material response; their availability into the FEM codes.

As example the widely used Johnson-Cook (JC) relationship [9] has been calibrated by using the experimental results obtained at several strain rates. The parameters are shown in Table 2. Only isotropic hardening and strain-rates hardening have been considered, due to the unavailability of temperature data.

\subsection{Material model and Finite Element simulation of the SHTB}

In order to verify the material model correctness the identity between the experimental and the simulated output
Table 2. Johnson-Cook parameters for the analysed materials.

\begin{tabular}{|c|c|c|c|}
\hline $\begin{array}{c}\boldsymbol{A} \\
{[\mathrm{MPa}]}\end{array}$ & $\begin{array}{c}\boldsymbol{B} \\
{[\mathrm{MPa}]}\end{array}$ & $\begin{array}{c}\boldsymbol{n} \\
{[-]}\end{array}$ & $\begin{array}{c}\boldsymbol{C}_{\text {mean }} \\
{[-]}\end{array}$ \\
\hline 1763 & 3367 & 0.4873 & -0.01566 \\
\hline
\end{tabular}

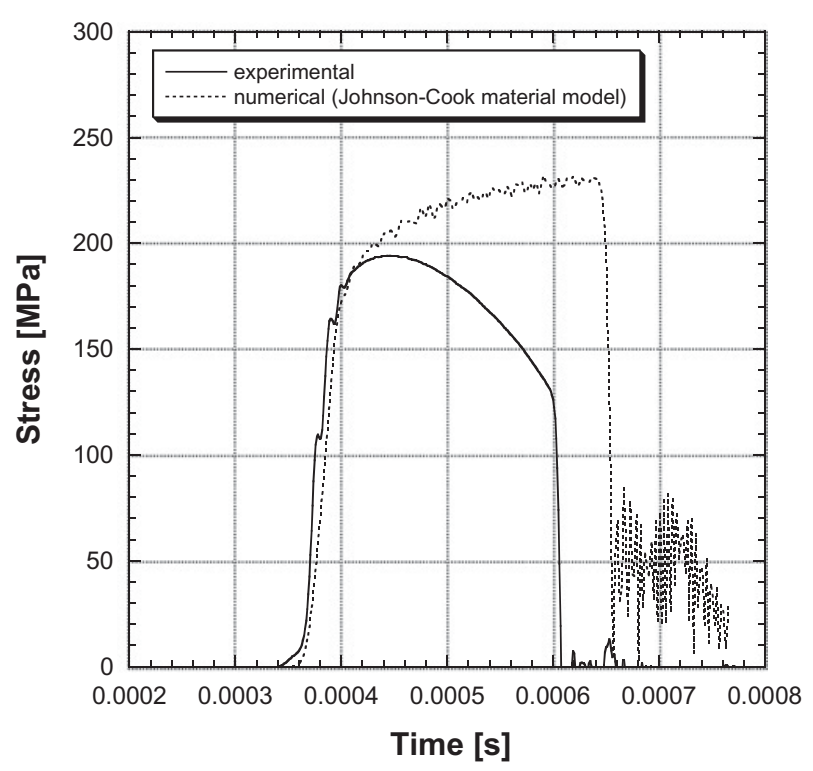

Figure 10. Comparison between experimental and simulated, by Johnson-Cook model, of the signal in output bar.

bar gauge record in the dynamic tensile test using JC model and *MAT_PIECEWISE_LINEAR_PLASTICITY model, available in the LsDyna code, was checked.

The use of the JC model, with the parameter shown in Table 2, into the FE simulation of the SHTB generates the output bar stress shown in Fig. 10.

By comparing the FE simulations of the SHTB using the *MAT_PIECEWISE_LINEAR_PLASTICITY model in correspondence of the output strain gauge and the experimental response of the armour steel it is possible to generate the material stress-strain data. Figure 11 shows the output gauge signals comparison in that case.

The constraints due to the fixed interpolation rule in the JC model origins difference respect the real response. In particular the use into the JC interpolation of the minimal stress difference criteria moves the necking point leading to increased deformation energy. The stress/strain/strainrate data point obtained by the SHTB simulation are expected to be more realistic because the breakage time and the consequent plastic work are controlled by the experimental output signal.

\subsection{Material model and FE simulation of blasting}

The differences between the two models can be focused by mean of a numerical example. A shell structure of size $1300 \times 1300 \times 0.13 \mathrm{~m}$, with $10 \mathrm{~mm}$ thickness is subject to a blast loading due to the explosion of $20 \mathrm{~kg}$ of TNT $200 \mathrm{~mm}$ below the centroid. The event was modelled with LS-Dyna solver.

Two material models were assigned to the structure, by means of the JC form and the data point. Finally, the two responses are compared. The two cases internal energy 


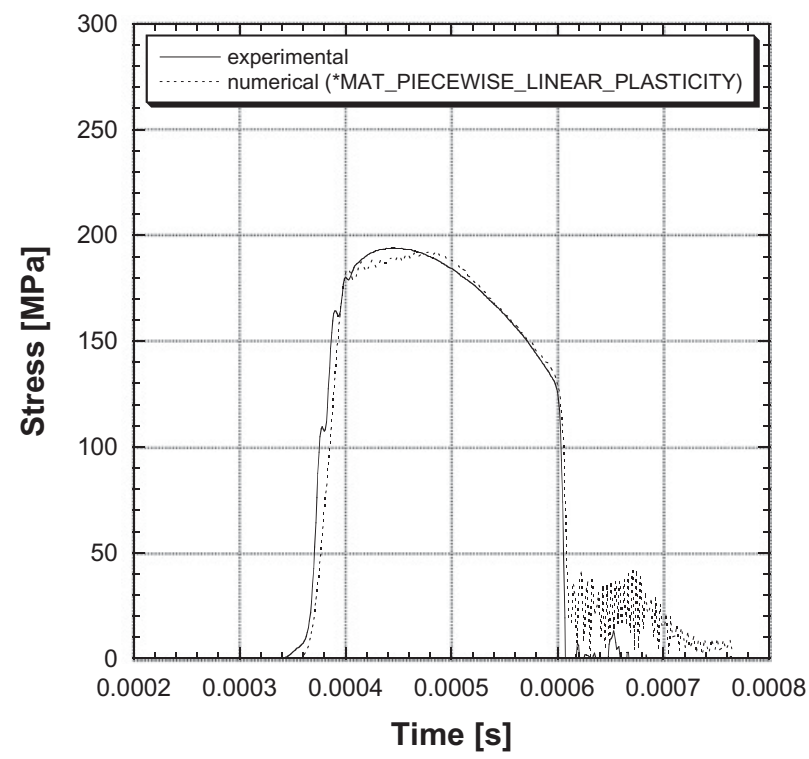

Figure 11. Comparison between experimental and simulated, by *MAT_PIECEWISE_LINEAR_PLASTICITY, of the signal in output bar.

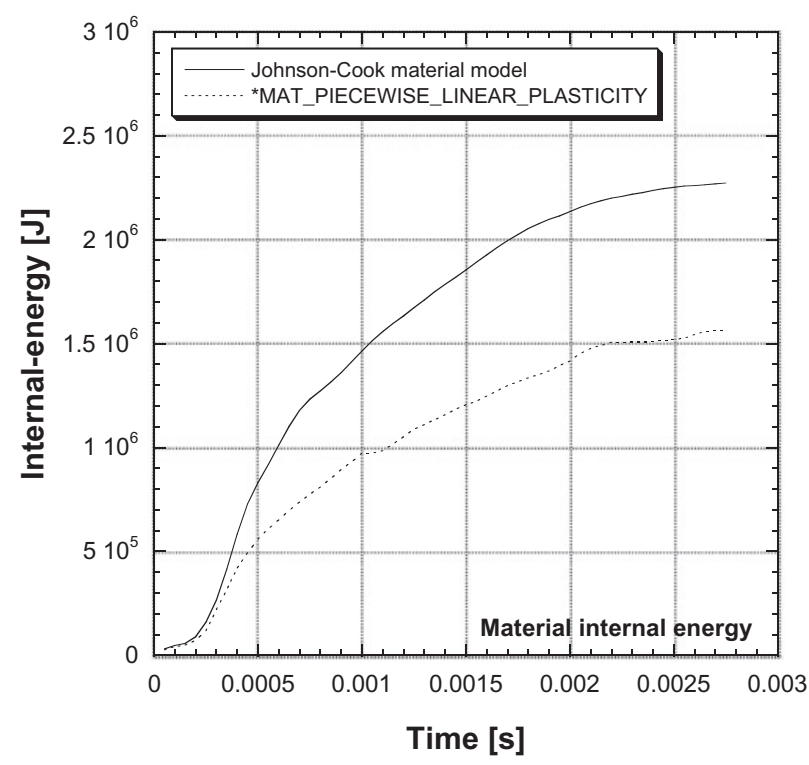

Figure 12. Material internal energy time history comparison.

(Fig. 12) such as the final deformation (Fig. 13) shows relevant differences.

\subsection{Remarks}

A drawback of the JC material model can be found in the respect of the necking point that affects the deformation energy of the material. Indeed the interpolation based on the real stress-strain does not constrain the necking point, while an interpolation based on the necking point does not respect the yield point or the ultimate tensile strength.

The JC material model can be tuned to single cases to fit the experimental evidences. This does not ensure the applicability of the JC material model to other geometrical and loading conditions. For material with high ultimate deformation, the problem increases in evidence.

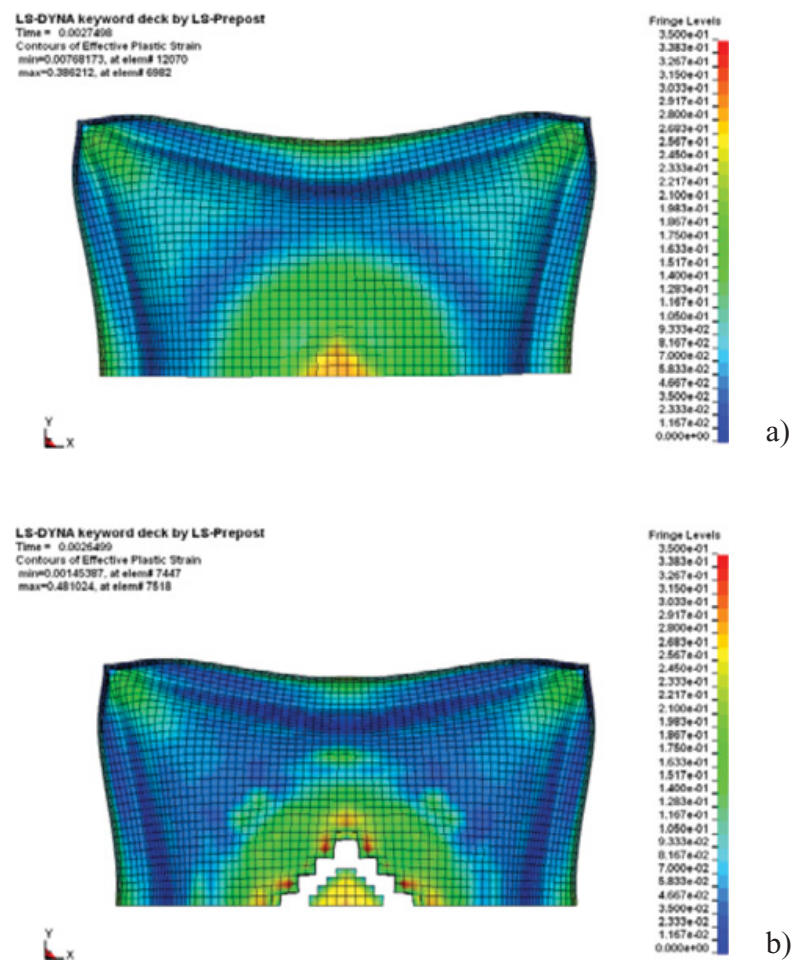

Figure 13. Contour of equivalent plastic strain during blasting: a) JC material model b) *MAT_PIECEWISE_LINEAR_PLASTICITY.

The previous inconvenient can be avoided using a material definition by using a tabular form into the space of stress, strain and strain rate. This simple form better reproduces the experimental response of the material.

When this table is produced, by using the finite element simulation of the SHTB, the local strain rates are considered with significant advantages in the material model reliability.

To obtain univocal definition of material parameters, an increased of the tests number and the use of automatic optimizators are required.

With reference to the previous numerical example, differences of $40 \%$ in deformation energy due to different material characterization were found.

\section{Conclusion}

The present work reveals that the armour steel investigated is low strain rate sensitive in the strain rate range from $0.001 \mathrm{~s}^{-1}$ to $1000 \mathrm{~s}^{-1}$ under uniaxial tension. In the true stress versus true strain curves a moderate increase of strain hardening in the material with the increasing strain rate was observed. The true fracture stress as well as the reduction of cross section area at fracture, increases with the increasing strain rate. Thanks to the length of the SHTB a quite low strain rate were obtained.

The Johnson-Cook model was calibrated using the experimental results. By reverse analysis a *MAT_ PIECEWISE_LINEAR_PLASTICITY material model was also obtained. The reliability of the two models was verified by mean of FEM simulation of the SHTB test. 
Finally, a numerical assessment was performed simulating a blast event on a steel plate by using the two material models. This comparison showed differences of $40 \%$ in deformation energy.

\section{References}

[1] G. Riganti, E. Cadoni, Mat. Des. 57, 156-167 (2014).

[2] E. Cadoni, M. Dotta, D. Forni, S. Bianchi, H. Kaufmann, EPJ WoC 26, 05004 (2012).

[3] E. Cadoni, M. Dotta, D. Forni, S. Bianchi, Appl. Mech. Mat. 82 124-129 (2011).
[4] E. Cadoni, L. Fenu, D. Forni, Constr. Build. Mat. 35, 399-407 (2012).

[5] D. Asprone, E. Cadoni, A. Prota, , ACI Struct. J. 106, 523-529 (2009).

[6] E. Cadoni, M. Dotta, D. Forni, P. Spätig, J. Nucl. Mat. 414(3), 360-366 (2011)

[7] E. Cadoni, M. Dotta, D. Forni, N. Tesio, C. Albertini, Mat. Des. 49, 657 - 666 (2013).

[8] C. Albertini, E. Cadoni, G. Solomos, Phil. Trans. Roy. Soc. A: 372, 20130197, (2014).

[9] Johnson, G.J., Cook, W.H. Proceedings of the Seventh International Symposium on Ballistics, The Hague, 1983, pp. 541-547. 